\title{
En algún lugar entre todas partes y ninguna parte: el viaje en la era de la Gestell o encuadre digital
}

\author{
Christopher A. Howard \\ College of Humanities and Social Sciences \\ Massey University (Auckland, Nueva Zelanda) \\ c.howard@massey.ac.nz \\ Wendelin Küpers \\ Karlshochschule International University \\ wkuepers@karlshochschule.de
}

En algún lugar entre todas partes y ninguna parte: el viaje en la era de la Gestell o encuadre digital (Resumen)

El siguiente artículo estudia las prácticas tecno-nómadas de movimiento $\mathrm{y}$ organización en viajeros globales y en red. Trabajando sobre un estudio de caso etnográfico de un viaje por Nepal y la India, se centra en las experiencias, movimientos y prácticas nómadas que incluyen, entre otras, las relaciones de los viajeros con el empleo y con la "interlocalidad". En particular, se exploran las formas del viajar mediadas por la tecnología digital y el papel que desempeña en ellas la idea de "residencia en el des-distanciamiento" en lo que denominamos, siguiendo a Heidegger "Gestell digital" (el término Gestell fue usado por Heidegger para describir lo que subyace en la tecnología). Se analizan también algunas de las implicaciones del medio y las prácticas tecno-nómadas, y como éstas manifiestan y reflejan tendencias sociales más amplias, incluyendo la hiper-conectividad, la dis-conectividad y las trayectorias narrativas no lineales caracterizadas por ser cada vez más móviles, globales y contingentes. Como conclusión, se discuten algunas implicaciones para un enfoque más sensible y responsable del espacio, para el desarrollo sostenible del viajar y el vivir, así como el significado de una ética de lo que Heidegger llamó Gelassenheit (serenidad para aceptar y rechazar al mismo tiempo el mundo técnico).

Palabras clave: Heidegger, nomadismo, tecnologías móviles, lugar, viaje, movilidad. 
Somewhere between everywhere and nowhere: travelling in the age of digital Gestell or framing (Abstract)

The following article describes tech-nomadic practices of moving and organizing of travelers situated and placed in global and networked contexts. Drawing upon an ethnographic case study in Nepal and India, we focus on travelers and their nomadic movements, experiences and practices, which included among other, those of work in relation to their 'inter-placedness'. In particular, we explore digitally mediated forms of travelling and the role of "dwelling in de-distancing" in what we call, following Heidegger, 'digital Gestell' (The word Gestell or Gestell was used by Heidegger to refer to what lies behind technology). Finally, the paper discusses some implications of the described tech-nomadic milieu and practices, as manifesting and reflecting broader social trends, including hyper and dis-connectivity, and non-linear narrative trajectories characterized as becoming increasing mobile, global and contingent. By concluding, we discuss some implications for a more place-responsive and responsible approach for sustainable traveling and living, as well as the significance of an ethos of what Heidegger called Gelassenheit (the attitude of releasment to accept and reject, at the same time, the technological world).

Keywords: Heidegger, nomadism, mobile technologies, place, travel, mobility.

\section{No estoy como cuerpo encapsulado en un lugar y me desplazo a un lugar; por ejemplo, no me desplazo a la salida. De alguna manera ya está uno en la salida, estoy allí porque aguanto el espacio y sólo así puedo atravesarlo. Martin Heidegger ${ }^{1}$.}

Por lo tanto, la fórmula de los procesos de modernización es la siguiente: el progreso es el movimiento hacia el movimiento, el movimiento hacia un mayor movimiento, el movimiento hacia el aumento de la movilidad. Peter Sloterdijk ${ }^{2}$.

El mundo es un lugar y un mundo de lugares. Viajar es moverse en el espacio-tiempo entre dos puntos. Aunque los viajeros están siempre emplazados en algún lugar, los medios físicos y tecnológicos permiten al ser humano extenderse más allá de su propio cuerpo y ubicarse más allá de un emplazamiento espacio-temporal inmediato. Ahora más que nunca, las formas tecnológicas de vida revelan el estar-en-el-mundo como un evento nómada que tiene lugar aquí, allá y en muchos otros lugares. Las vidas contemporáneas y las formas de organización se caracterizan por ser cada vez más móviles e interlocalizadas. Así, la voluntad y la disposición de estar "en movimiento" parecen haber desarrollado un fuerte imperativo en nuestros (supuestos) tiempos líquidos ${ }^{3}$.

\footnotetext{
${ }^{1}$ Heidegger, 1978, p. 359.

2 Sloterdijk, 2006, p. 37.

${ }^{3}$ Ver por ejemplo, Bauman, 2007; Urry, 2007.
} 
A medida que los múltiples tipos de movilidad parecen producir un "patrón entrelazado de la vida"4, la movilidad ha cambiado, en lo que ha sido descrito como movimientos más complejos, reales e imaginarios, de sujetos, objetos, capital, conocimiento y poder ${ }^{5}$. Esta movilidad transforma profundamente las subjetividades, identidades y relaciones sociales, pero también el orden y las relaciones socioeconómicas y políticas, e influye en la vida y las prácticas del cosmopolitismo contemporáneo individual, en las organizaciones y en las instituciones ${ }^{6}$. En lo que ha sido llamado el paradigma de las nuevas movilidades ${ }^{7}$, las relaciones, conexiones, y tecnologías móviles, así como el lenguaje de la movilidad, parecen ser ahora "más reales" que los lugares, estructuras y entidades territorialmente fijos ${ }^{8}$.

Este artículo describe prácticas nómadas de viajeros. Nos centraremos en los viajeros y sus movimientos, experiencias y prácticas nómadas, que incluyen, entre otras, las prácticas de trabajo. A medida que los límites entre viajes de ocio, trabajo y estilos de vida móviles se tornan cada vez más borrosos ${ }^{9}$, las prácticas de los viajeros arrojan luz sobre el rol que juega el nomadismo en sus formas de organizarse. El uso de dispositivos móviles está influyendo en la relación entre la localización de los viajeros y sus experiencias nómadas ${ }^{10}$.

En la era global de sistemas de comunicación en red y gracias a las tecnologías móviles, los viajeros son, más que nunca, capaces de moverse imaginaria, corporal y virtualmentey estar (tele)presentes en muchos lugares y tiempos a la vez. En un mundo cada vez más interconectado, las posibilidades para acceder y habitar múltiples realidades y pasar a estar (be (com)ing) "interlocalizados" se intensifican. Enmarcadas por el entorno móvil y tecnológico de la era de la información, las prácticas de los medios de comunicación contemporáneos revelan nuevos modos de viajar-en, habitaren y finalmente estar-en-el-mundo. Al examinar ciertas prácticas tecnológicas, narrativas y dinámicas relacionales de los viajeros hiper-móviles, exploramos las reconfiguraciones del lugar, espacio y tiempo y cómo se sitúan los sujetos en la era de la tecnología móvil y la movilización.

Reconociendo que el viajar no es un hecho aislado que se produce exclusivamente aquí o allá, ahora o después, este trabajo gira en torno a una concepción fenomenológica de la "interdeslocalización". El viajar es considerado así un acontecimiento relacional y procesual, en el que los viajeros traen experiencias pasadas, recuerdos y fantasías -así como los hábitos, prejuicios y esquemas de conocimiento del hogar terrenal- a sus encuentros con otros mundos. En otras palabras, los viajeros traen sus mundos y, por lo tanto, "a ellos mismos", a esos otros mundos. El viajar, por lo tanto, puede ser visto como un encuentro recursivo y creador de mundos, como un proceso en espiral en el que la creación de mundos siempre parte de mundos que ya están presentes: la creación es en realidad una reconstrucción ${ }^{11}$.

\footnotetext{
${ }^{4}$ Hannam et al., 2006, p. 2.

${ }^{5}$ Elliott\&Urry, 2010; Urry, 2007.

${ }^{6}$ Beck\&Sznaider, 2006.

${ }^{7}$ Sheller\&Urry, 2004, p. 207.

${ }^{8}$ Szerszynski\&Urry, 2006, p. 127.

${ }^{9}$ Rojek, 2010.

${ }^{10}$ Roberson, 2001.

${ }^{11}$ Rojek, 2010.
} 
En el desarrollo de una comprensión fenomenológica del lugar y el emplazamiento, destacamos en este artículo el papel de las tecnologías móviles en la mediación del lugar, las experiencias de viajes y la construcción de la realidad. En primer lugar, exploramos el lugar y la ubicación como eventos de vida mundanos, relacionales o procesuales. A continuación, se investiga el papel que las tecnologías móviles desempeñan en la mediación y la reconfiguración de viajes corporales y experiencias de lugar y emplazamiento, respectivamente interdeslocalizadas. Observando la tendencia de viajar con y a través de las tecnologías móviles, argumentamos que las tecnologías actuales y las prácticas correspondientes están alterando radicalmente lo que significa viajar, tener la experiencia de viajar y estar en un lugar. Las prácticas de uso de tecnologías móviles por parte de viajeros en Nepal e India que estudiamos en este artículo revelaron una tendencia a entrar y salir de "paisajes planetarios"12 a través de "personalidades portátiles" 13 definidas por redes sociales. Esta forma de movilidad y emplazamiento apunta no solo a una forma de viajar enmarcada digitalmente, sino también a una forma de estar-en-el-mundo, que siguiendo a Heidegger, llamaremos "Gestell digital".

A medida que los fenómenos tecno-nómadas y las prácticas móviles tecnológicas se manifiestan, reflejan una tendencia social más amplia en las orientaciones de vida y trayectorias narrativas. Como conclusión discutimos algunas implicaciones para un enfoque más sensible y responsable para con el lugar, una mirada al viaje y la vida sostenibles, así como la importancia de una ética de la Gelassenheit ${ }^{14}$.

\section{Lugares corporizados y la ubicación como evento de la vida mundana y el viajar}

El ser es ser en un lugar, y el ser un fenómeno, en apariencia, es similar al ser colocado, o, si se puede decir, a acontecer. Jeff Malpas $^{15}$

Para los viajeros, el acto de viajar es un "evento" corpóreo (Ereignis), en el sentido fenomenológico de un "acontecimiento" o "algo que tiene lugar", que es un hecho tanto espacial como temporal. Si viajar es un evento corpóreo que tiene lugar, nos preguntamos dónde y cómo estos acontecimientos sucedieron para los viajeros que viajaron a Nepal e India que hemos estudiado, mientras que aún permanecían conectados a mundos vitales más amplios. Consideramos a continuación qué enmarcó las condiciones de estos hechos particulares y lo que este tipo de eventos revelaron acerca del viajar y el (pasar a) ser en las condiciones tecnologizadas de la modernidad tardía. Aunque los viajes, incluso los viajes etnográficos, se basan en la experiencia del "estar allí," nuestra preocupación aquí es comprender lo que "estar allí" y "estaren-el-mundo" significan, sobre todo cuando el "estar" no se produce solo "aquí" o "allí,, es decir, en lugares discretos y en cuerpos aislados y vinculados a un lugar.

\footnotetext{
${ }^{12}$ Goodman, 1978, p. 6.

13 Augé, 2008.

${ }^{14}$ La palabra Gelassenheit (en alemán en el texto original en inglés) es de difícil traducción al castellano. Suele ser usada para hacer referencia al abandono en el pensar y el ser, a dejarse llevar por el pensamiento y la experiencia, liberarse, dejarse ir, serenarse, estar en calma y desapego.

${ }^{15}$ Malpas, 2012a, p. 46.
} 
Resonando con las nociones heideggerianas del ser humano como el "ser ahí" $(\text { Dasein })^{16}$, consideramos el estar-en-el-mundo de los viajeros como un evento que se dispersa entre horizontes móviles y una multiplicidad de organismos, lugares, espacios y tiempos. Estamos particularmente interesados en cómo este evento se ve afectado por las fuerzas de dis- e hiper- conectividad situadas en la era de la Gestell digital. Para llevar a cabo dicha investigación, se siguió una comprensión fenomenológica radicalizada del lugar, como se describe brevemente a continuación.

Diferentes y más que meras ubicaciones o contenedores, los lugares, espacios, el tiempo y el cuerpo son condiciones básicas para la existencia. En y a través de espacios temporalizados y lugares, es donde el mundo se manifiesta a los seres humanos y donde el estar-en-el-mundo sucede.

A diferencia de los enfoques estáticos, dualistas y des-temporalizados, una comprensión fenomenológica considera estos elementos interdependientes de la experiencia vivida y los motivos existenciales de todos los eventos de la vida mundana. Equipados con un marco espacial, los cuerpos vivos median y navegan dentro y hacia lugares a través de prácticas socio-culturales "ambientalizadoras" primordiales y específicas ${ }^{17}$. Los movimientos, los ritmos y las interacciones entre sujetos corpóreos y lugares facilitan la co-creaciónde "lugares-paisajes", en los que los cuerpos y los ambientes son "homólogos congruentes" ". Como Merleau-Ponty señala, "lejos de que el ser de mi cuerpo sea para mí tan solo un fragmento del espacio, no habría espacio para mí si no tuviera cuerpo"19. El cuerpo acoplado y el mundo forman una conexión espacio-temporal dinámica que siempre se percibe, media y orienta a través de un cuerpo que está siempre emplazado.

El "emplazamiento" refiere a una colocación inmediata y concreta en la que se encuentra la interacción entre el cuerpo vivo y el lugar ${ }^{20}$. Como apunta Edward Casey, "los cuerpos pertenecen a los lugares como los lugares pertenecen a los cuerpos... el lugar es donde está el cuerpo" 21 . El estar emplazado implica detectar, sentir, moverse, orientarse, pensar y actuar a través de un cuerpo que está co-constituido por los lugares y espacios con los que se haya involucrado en la práctica. El lugar es por lo tanto "una estructura que comprende la espacialidad $y$ la temporalidad, la subjetividad $y$ la objetividad, el yo y los otros 'otros'"22. De esta manera, los lugares se entienden mejor como procesualidades relacionales que no son fijas o cerradas, sino estructuras relativamente abiertas y emergentes.

\footnotetext{
${ }^{16}$ Heidegger, 1978.

${ }^{17}$ Bachelard, 2008; Casey, 1993 y 2001; Heidegger, 1996; Ingold, 2000; Küpers 2010.

${ }^{18}$ Merleau-Ponty, 1962.

${ }^{19}$ Merleau-Ponty, 1962, p. 117.

${ }^{20}$ Dreyfus, 2002 y 2009; Malpas, 1999 y 2006; Merleau-Ponty, 2002.

${ }^{21}$ Casey, 1993, p. 3-23.

${ }^{22}$ Casey, 1993, p. 102-103.
} 


\section{EI viajar entre lugares como eventos relacionales y procesuales}

Un enfoque relacional y orientado al proceso entiende el lugar y el espacio como los resultados emergentes de procesos inter-relacionales. Los espacios y lugares son fenómenos dinámicos, temporales y multidimensionales, compuestos por dimensiones físicas, ambientales, socio- culturales y personales. Relacionalmente, un lugar en particular no ha de ser visto como algo limitado y estático, sino como un espacio abierto, con capas, múltiple y emergente, dentro de un proceso disperso e inherentemente indeterminado en continua reconfiguración. Como tal, los lugares son procesualidades que deben ser entendidos como eventos, más que como cosas ${ }^{23}$.

Como señala Massey ${ }^{24}$, el evento del lugar no es pre-dado o "intrínsecamente coherente", sino más bien un producto contingente de "colocación-conjunta". El "aquí" pasa a ser un lugar de "encuentro", donde las narrativas espaciales se reúnen o forman configuraciones y coyunturas de trayectorias con sus propias temporalidades. De esta manera, las preguntas respecto al tiempo se vuelven tan problemáticas como las de lugar.

Más allá de los actores individuales, el acontecer de la movilidad global implica vastas redes, configuraciones, coyunturas y redes de relaciones entre agentes humanos y objetos. Cualquier viaje a Nepal o India, por ejemplo, se hace posible y se constituye gracias a culturas locales, instituciones, capital circulante, sistemas de información y comunicación, actores, edificios, aviones, automóviles, trenes, fuentes de energía eléctrica y petróleo, cadenas de comida y agua, organismos geográficos, plantas y cuerpos de animales y así sucesivamente. Los recursos y las relaciones sociomateriales locales y globales están movilizadas e implicadas en el proceso o acontecimiento de un solo viaje, que es realmente un micro-evento que ocurre dentro de un sistema mucho más grande. El seguir la ontología de un evento es importante y revelador, ya que se centra en las relaciones entre tiempo, espacio, lugar, cuerpos y cosas, y en la contingencia de órdenes y el potencial para la ruptura o transformación de las condiciones existentes ${ }^{25}$. A medida que los acontecimientos están ocurriendo en todas partes y todo el tiempo, estamos atrapados en un mundo de movimiento y devenires en el que cualquier orden sigue siendo superficial y volátil, lo que nos deja un futuro contingente e indeterminado ${ }^{26}$.

Mientras que todos los lugares se someten a procesos de hacer y rehacer, ciudades globales y zonas turísticas como Dharamsala, Katmandú, Pokhara y Darjeeling, como encrucijadas cosmopolíticas, están especialmente sujetas al cambio y reordenamiento en medio de confluencias globales de personas, objetos e información ${ }^{27}$. Estos lugares se (re)producen a través de combinaciones trabajadas en red de turistas y performances o prácticas locales, todo lo cual es posible a través de los flujos de capitales, personas, objetos, organizaciones, instituciones, sistemas de información, máquinas, edificios, señales, transporte y otras infraestructuras ${ }^{28}$. Como "lugares para

\footnotetext{
${ }^{23}$ Malpas, 2012b; Massey, 2005.

${ }^{24}$ Massey, 2005, p. 139-141.

${ }^{25}$ Massey, 2005.

${ }^{26}$ Massumi, 2002.

${ }^{27}$ Anderson \& Harrison, 2010; Deleuze \& Guattari, 2004.

${ }^{28}$ Clifford, 1997; Mydans, 2008.
} 
actuar/jugar y lugares en juego", las zonas turísticas se encuentran en una "espiral de procesos globales" que existen en "diferentes etapas y localidades dentro de los flujos globales",29.

Al tener lugar dentro de flujos y corrientes culturales mayores, consecuentemente "se producen nuevos lugares para cada nueva generación", mientras se dejan atrás los lugares que ya no son nuevos. Este patrón representan un riesgo para las comunidades de acogida y los entornos locales, que se ven afectados por el desarrollo turístico, como ha advertido la crítica ofrecida por antropólogos y geógrafos hacia el turismo ${ }^{30}$. El estar "ahí fuera" y encontrar mundos extraños o foráneos no significa simplemente dejar atrás mundos natales y las identidades correspondientes. Al contrario, los mundos de origen acompañan a los viajeros a los nuevos mundos, del mismo modo que las personas llevan sus historias y prejuicios a cualquier encuentro dialéctico. El mundo-hogar es transportado por los viajeros dentro de sí mismos, como las costumbres, el conocimiento tácito, las actitudes y disposiciones culturales, los recuerdos y los imaginarios. También viene inscrito en la disposición(hexis) corporal de los viajeros y en los artefactos materiales que llevan, como ropa, mochilas, libros, música, medicinas y otros artículos personales.

El viaje entre mundos-hogar corporizados también puede manifestarse en las interacciones sociales con otros viajeros y en la disponibilidad de alimentos y bebidas familiares, como los cafés con leche y capuchinos que resultaron estar fácilmente disponibles en muchas de las localidades. Cada vez más, el mundo-hogar -"hogar" en tanto que lugar-mundo del que se parte y/o una red de personas y lugares interconectados que abarcan el mundo- acompaña a los viajeros en sus desplazamientos y vivencias temporales en otros mundos mediante las tecnologías móviles.

\section{Las tecnologías móviles y la "inter-deslocalización"}

El trabajo de campo realizado en Nepal e India confirmó el uso ubicuo de las tecnologías móviles de comunicación por los viajeros. Más allá de las visitas ocasionales a un ciber-café, que eran práctica común en los viajes desde finales de los años noventa, el hecho de que muchas personas viajaban con ordenadores portátiles y/o dispositivos portátiles como teléfonos inteligentes, iPads, iPods y iPhones, demuestra que la llegada de una nueva era tecnológica y un modo correspondiente de viajar han pasado a ser una parte intrínseca del viaje (post-)moderno. Con las tecnologías móviles y la creciente presencia de conexión inalámbrica a Internet en los lugares frecuentados por los viajeros, vimos a éstos pasando grandes periodos de tiempo junto a sus dispositivos de comunicación portátiles. De hecho, se hizo difícil entrar en contacto con los viajeros "que se encontraban" en los cafés, restaurantes y casas de huéspedes, porque estaban, a menudo, profundamente absortos usando estos dispositivos móviles, manteniendo las conexiones con sus respectivos ámbitos de origen al mismo tiempo que desconectados de los ambientes localizados.

\footnotetext{
${ }^{29}$ Urry, 2007 y 2011, p. 119.

${ }^{30}$ Sheller \& Urry, 2004, p. 8-9.
} 
Como las observaciones del trabajo de campo y la literatura de investigación demuestran, en los últimos dos decenios, ha habido una difusión o "dispersión" de Internet y las tecnologías móviles a través de múltiples dominios de la vida, incluyendo la peregrinación y las vacaciones ${ }^{31}$. Estas tecnologías permiten transportar con uno mismo la familiaridad, las rutinas y la continuidad del mundo-hogar. Urry y Elliot $^{32}$ acuñaron el término "movilidades en miniatura" para describir la proliferación y el impacto de los dispositivos de comunicación digital como teléfonos móviles, ordenadores portátiles, tabletas y teléfonos inteligentes, cada vez más compactos y sofisticados. Observaron que las tecnologías telefónicas y en red son una característica sobresaliente de la sociedad de la información -o del ordenador- que ha penetrado rápidamente en el tejido social de la vida móvil actual. Si bien las "movilidades en miniatura" abren posibilidades para reforzar y aumentar la movilidad, es importante destacar cómo las tecnologías de red cambian los contextos sociales y transforman las experiencias corporizadas del lugar, el espacio y el tiempo, así como del yo y los demás.

Una de las primeras interacciones que tuve con una viajera en Nepal tuvo lugar, precisamente, a través de ordenadores portátiles. Nuestro encuentro fue en el bar situado en la terraza de la azotea del hotel Vajra, donde me dijeron que había la mejor señal inalámbrica de Internet. Yo ya llevaba tres días en Nepal y sentí que había postergado el envío de un correo electrónico a mi familia en California y a mi pareja en Nueva Zelanda, que probablemente se estarían preguntando por mí. En el pequeño bar, me uní a una mujer rubia de unos cuarenta años que vestía ropa colorida y de seda -aparentemente fabricada a nivel local- y lucía un rojo tilaka hindú en la frente, en el espacio del "tercer ojo". Al levantar la mirada de su computadora portátil, forzó una sonrisa rápida y un "hola", desviando luego la mirada de vuelta a su pantalla. En un esfuerzo por entablar conversación, le pregunté la contraseña del Wi-Fi e hice un comentario sobre la agradable ubicación de nuestro "hotspot".

La terraza del tercer piso del Hotel Vajra ofrece una vista panorámica de Katmandú y Patan, con la plaza Dhurbur al oeste y el Himalaya hacia el nordeste. Antes de instalarme en el bar, pasé un buen rato contemplando las lejanas montañas, imaginando el Tíbet un poco más allá. Después de darme la contraseña y advertirme de los frecuentes cortes de energía que ocurren en Katmandú -el próximo estaba previsto para dentro de una hora e impediría el acceso a Internet durante al menos diez-, la mujer y yo entablamos una conversación superficial. Me enteré de que estaba en Katmandú para un retiro de yoga y meditación, y de que también haría un poco de senderismo en la región de Dolpo, en el norte del país. Dada su confianza y familiaridad con los nombres y las regiones de Nepal así como su actitud relajada y su forma de vestir, deduje que era uno de sus muchos viajes al país. Mi intuición era correcta, ya que me enteré que venía a Nepal desde Seattle cada año y pasaba aquí uno o dos meses. Al parecer no estaba interesada en escuchar mi historia. Sus ojos cayeron pronto de vuelta a su pantalla y se hizo el silencio. Tomando esto como una señal de que nuestra conversación había terminado, yo hice lo mismo. Mirando por la ventana, en la azotea del hotel Vajra, justo por encima del clamor de Katmandú, vi los cuervos volando a través de las siluetas borrosas de la cordillera del Himalaya antes de volver

\footnotetext{
${ }^{31}$ Bruner, 1991; Cohen, 1988; Crick, 1989; Gupta, 1999; Gurung \& Seeland, 2008; Nash, 1996; Nepal, 2000; Shackley, 1994 y 1995; Terzidou \& Stylidis, 2008

${ }^{32}$ Elliot \& Urry, 2010; Hjorth, 2012; MacKay \& Vogt, 2012.
} 
los ojos a mi propia pantalla. Una frente al otro, con los ojos brillando en los píxeles parpadeantes de las pantallas de cristal iluminadas, un ritmo constante de clics y toques nos llevó en otras direcciones, a otros lugares. Nuestra presencia se adentró en los portales digitales, fuera de Katmandú, hacia nuestras "esferas de lo propio", hacia nuestros respectivos lugares-mundos. Leí y escribí correos electrónicos a mi familia en California, mi pareja en Nueva Zelanda y a mis amigos recientemente casados en Japón, mientras ella plausiblemente se conectaba con sus propios seres queridos. Al igual que la gente a la que nos conectábamos en diferentes lugares del mundo, en ese pequeño bar en la azotea, la mujer y yo estábamos juntos, pero separados. Muchos encuentros posteriores se llevaron a cabo de esta manera y me hicieron pensar sobre la naturaleza y la calidad de las experiencias que los viajeros estaban teniendo en términos corpóreos. Más específicamente, me pregunté qué sucedía cuando los viajeros se sintonizaban con el mundo digital y fuera de los mundos locales.

\section{La superposición de las movilidades virtuales y corporales: las consecuencias humanas}

Edward Casey comenzaba un ensayo reciente planteando la pregunta: “¿Qué significa la tecnología inalámbrica para nosotros como seres humanos corporizados?"33. A partir de la misma, argumenta con fuerza que las características fundamentales de nuestra existencia sufren el abandono en un mundo sin cables, en el que cambia nuestra experiencia de nosotros mismos, de los otros y del mundo viviente. Su primera crítica es a cuenta del "valor insustituible" que posee el estar con otras personas cara a cara, en el mismo lugar: "simplemente no hay sustituto para la lectura matizada de la cara del otro y, de hecho, todo su cuerpo... las expresiones y diálogos solo posibles en presencia de una persona son de una complejidad y alcance que simplemente no pueden ser experimentados de otro modo" ". Casey también critica la "ilusión" de la disponibilidad omnipresente que caracteriza la era de las tecnologías inalámbricas, la idea de que otra persona está disponible para mí simplemente porque llevo un móvil o un portátil. Admitiendo que ser capaz de llevar a todo el mundo "conmigo", en mi libreta de direcciones, donde quiera que vaya, es útil en muchas ocasiones y hasta necesario en otras, Casey señala que el yo corporal emplazado no puede estar en todas partes a la vez. Y, sin embargo, dice Casey, "la presencia tecnológicamente mediada de otra persona trae consigo la presunción ilusoria de que puedo, sin costo o pérdida, reemplazar al otro concreto por su icono". ${ }^{35}$ Junto con las consecuencias que presenta para la interacción dialógica, para Casey el mundo inalámbrico hace que los seres humanos pierdan el contacto con "el requisito fundamental para la existencia" -el cuerpo y el lugar-:

Cuando uso las tecnologías inalámbricas que me llevan fuera de lugar, no importa cuan conveniente o práctico sea ese movimiento, me estoy moviendo hacia una experiencia sin cuerpo que me priva de la base misma de mi identidad personal e interpersonal. ${ }^{36}$

\footnotetext{
${ }^{33}$ Casey, 2012, p. 175.

${ }^{34}$ Ibid, p. 175.

${ }^{35}$ Ibid, p. 175 .

${ }^{36}$ Ibid, p. 177.
} 
Además de separarnos de nuestro emplazamiento corporal inmediato, las tecnologías inalámbricas tienen importantes implicaciones para la experiencia del tiempo y del espacio. El flujo o cascada de imágenes y palabras que aparecen rápidamente en las pantallas a través de las redes digitales no contemplan el tiempo y el espacio. Juntan horizontes pasados y futuros en un presente eterno. Las relaciones pasadas, presentes y futuras dan paso a una sucesión de ahoras ahistóricos ${ }^{37}$, que llevan a lo que Eriksen ${ }^{38}$ llama "la tiranía del momento". Según Casey, no es que los horizontes temporales se cancelen o eliminen -"siguen existiendo para cualquier evento"- pero el "vínculo orgánico con el presente se corta":

En resumen, el tipo de transformación intrínseco a la experiencia completa del tiempo es corto
-circundado; se reduce a lo que "ahora" se ha convertido- y solo es en la medida en que es
puesto delante de mí en una pantalla de cristal líquido, pantalla de plasma u otra superficie
representacional. ${ }^{39}$

En Nueva Zelanda, antes de iniciar el viaje, había estado deliberando si llevar o no mi ordenador portátil y mi iPhone recién adquiridos, por razones similares a las expuestas por Casey. Me preocupaba el hecho de que viajar con estas tecnologías fuese perjudicial para la experiencia corporizada de estar en Nepal y la India. Después de todo, viajar y hacer etnografía, pensé, se basaban en "estar allí,, en experimentar la gente, los lugares y los mundos de la vida locales en todo lo posible, a través de la propia presencia y con la atención completa. Así, inicialmente había pensado en ir al campo con solo una libreta de papel y una pequeña cámara, para liberarme de lastre y participar plenamente de los lugares en los que me emplazaría a mí mismo. Otra razón para no llevar el ordenador y el iPhone tenía que ver con la preocupación por la seguridad: no quería pasar mi tiempo preocupándome de no perder o de que me robasen estos dispositivos (la razón por la que el portátil era nuevo era que me habían robado el anterior).

Mi hermano, periodista, logró convencerme de que sería conveniente documentar todo de la manera más completa posible. "Las tecnologías están ahí, ¿por qué no usarlas?", dijo afirmando lo tontamente obvio. Con sentimientos encontrados, seguí su consejo y entablé una estrecha aunque ambigua relación con mis "movilidades miniaturizadas". En el lado positivo, viajar con un iPhone me permitió tomar buenas fotos y vídeos, hacer grabaciones de voz y conectarme cuando había Internet inalámbrico disponible. Gracias a su discreción y multi-funcionalidad, pasé a considerar el iPhone una herramienta etnográfica y de viaje apropiada, y mis viajes e investigaciones empíricas no habrían sido lo mismo sin él. Tener una computadora portátil también me permitió escribir notas, organizarlas y editarlas sobre la marcha, descargar fotos, vídeos y grabaciones de voz del iPhone en bibliotecas que se organizan de manera automática, así como acceder a artículos y libros escaneados durante "el tiempo de inactividad". Esto significa que los procesos de recopilación y análisis de datos pasaron a estar cada vez más entrelazados y formar parte de la metodología móvil. A pesar de estas tecnologías avanzadas, seguí llevando conmigo un cuaderno escrito a mano por conveniencia y, supongo, sentimiento de nostalgia.

\footnotetext{
${ }^{37}$ Merleau-Ponty, 1962, p. 412-414.

${ }^{38}$ Eriksen, 2012, p. 175.

${ }^{39}$ Casey, 2012, p. 179.
} 
Como lugar que se representa como espacial, temporal y simbólicamente apartado del mundo moderno, la región del Himalaya parecía la antítesis de las tecnologías modernas, la velocidad y las exigencias de la era de la información. Como los medios dominantes y los viajeros contemporáneos siguen reiterando, la cordillera del Himalaya es considerada como un "horizonte perdido", un mundo misterioso, encantado, situado por encima y más allá de los ámbitos profanos. Situado literal y simbólicamente lejos de la moderna vida digital urbana, el Himalaya como un lugar "ahí fuera" es también un lugar "fuera del tiempo" 40 . Por otra parte, viajar en el Himalaya parecía centrarse en mover el cuerpo, no sentarse delante de una pantalla. Mientras que el senderismo, la escalada, apreciar magníficos paisajes naturales, la exploración de mundos de vida locales, practicar yoga y el voluntariado son experiencias significativamente corporales y sensuales de los viajes de muchas personas, también aprecié el uso muy frecuente de las tecnologías móviles entre los viajeros.

A pesar de mis temores iniciales, me di cuenta de que viajar con "movilidades miniaturizadas" era una práctica común en Nepal y la India, y, por lo tanto, se ha integrado en las experiencias y lugares de los viajeros (y anfitriones). La mayoría, como yo, llevan el ordenador portátil y/o teléfonos inteligentes y los puntos con Wi-Fi gratuita -que normalmente se encuentran en los cafés frecuentados por viajeros, restaurantes y casas de huéspedes- aparecían como puntos nodales que servían para orientar y coreografiar los ritmos diarios de los viajeros transportadores de móviles. Atender las cuestiones digitales se convierte en tejido de los ritmos diarios y rutinas. Los paisajes-lugares de viajeros que llevan los teléfonos se presentan de manera similar a lo que el geógrafo fenomenológico Seamon ${ }^{41}$ llama un "lugar ballet". Siguiendo a Merleu-Ponty, Seamon presta atención a las formas en las que se rigen los "cuerpos sujetos", en gran medida a los sistemas de percepción y conocimiento habituados y automáticos. Estos esquemas corporales sirven para orientar $\mathrm{o}$ coreografiar los movimientos y prácticas rítmicas que constituyen las experiencias diarias de los lugares. Tomadas en la experiencia corporal y percibidas como "extensiones" u "órganos" de las actividades corporales del cuerpo, las tecnologías móviles simplemente se convirtieron en parte de las experiencias del lugar de los viajeros en Nepal y la India.

\section{Tecnologías móviles y múltiples fases de viaje}

El uso de medios móviles se intensificaba durante los interludios en los centros turísticos urbanos como Katmandú, Pokhara y estaciones como Darjeeling y Dharamsala. Estos lugares disponen de servicios del mundo-hogar: en ellos, los alimentos y bebidas a los que los viajeros están habituados e Internet son más accesibles en comparación con pueblos, montañas y parajes más remotos que también fueron visitados. Así pues, las prácticas tecnológicas dependían tanto de la ubicación como de las fases específicas de los viajes. La mayoría de las personas con las que hablé estimaron que pasaban una o dos horas al día conectadas a Internet cuando estaban en los centros más urbanos y turísticos, a veces divididas en dos o tres sesiones.

\footnotetext{
${ }^{40}$ Fabian 2002; Ortner 2001; Said 1978.

${ }^{41}$ Seamon, 1979.
} 
Equipado con mis propias movilidades en miniatura y al igual que los participantes en mi investigación, yo también empecé a caer en el hábito de comprobar el correo electrónico a diario o casi a diario cuando estaba en dichos lugares. También pasé tiempo durante las tardes frente a mi portátil, escribiendo notas y reflexiones y organizando grabaciones digitales de voz, foto o vídeo grabadas en mi iPhone durante el día. La reflexión sobre mi uso frecuente de estos medios de comunicación móviles y el modo en que afectaban mi experiencia de los lugares por los que me movía se convirtió en algo cada vez más interesante. Dicho interés se intensificó al observar que no era ni mucho menos el único con este modo de viajar "tecnologizado". Durante los meses que pasé en Dharamsala, casi todas las mañanas daba un paseo por la ciudad con mi ordenador portátil o iPhone buscando un Espresso MoonPeak o un Rogpa Café, dos cafeterías que ofrecían conexión gratuita a Internet, servían café decente y eran muy populares entre los viajeros. Pese a que estas cafeterías estaban en el norte de la India y las regentaban jóvenes refugiados tibetanos, al entrar en ellas sentía como si me transportase a una escena que bien se podría dar en San Francisco o Wellington. En su interior sonaba música familiar y pronto me encontraba rodeado de una congregación de "cuasi-bohemios" sorbiendo espresso, tecleando en ordenadores portátiles, deslizando sus dedos sobre pantallas táctiles, leyendo libros y de vez en cuando hablando entre ellos. La sorprendente sensación de déjà vu al encontrar semejantes ambientes hogareños en el norte de la India era a la vez reconfortante y desconcertante; sin embargo, pronto pasó a ser algo extrañamente normal y razonable. Después de todo, era 2011 y la revolución digital ya había llegado, trayendo consigo un "paisaje planetario".

Al principio frecuentaba esos cafés, tanto en Dharamsala como en otros lugares que visitaba, como una manera de conocer viajeros (es decir, "participantes") cuya pista era difícil de seguir de otra manera, pues se movían constantemente. El café, la comida occidental, la conexión inalámbrica a Internet y un cierto sentido de familiaridad les atraía y generaba lugares de encuentro en los que yo "pasaba el rato" y entablaba conversación con quien estuviera dispuesto y no demasiado preocupado por su dispositivo móvil. ¿Qué hacen los viajeros en sus dispositivos móviles? Mirando sobre sus hombros en los cafés y preguntando descubrí que pasaban el tiempo enviando correos electrónicos o mensajes instantáneos, conectándose a Skype, enviando y viendo fotos, usando redes sociales como Facebook y Twitter, actualizando y leyendo blogs, mirando webs de noticias, viajes y ofertas de empleo, gestionando cuentas bancarias y tarjetas de crédito y viendo clips de vídeo.

Algunos trabajaban online, en cursos universitarios o incluso en tesis doctorales o de máster. Como me explicó una mujer australiana llamada Anna, que conocí en un café de Pokhara, era "más barato y divertido" trabajar en su tesis doctoral (en materia de derechos indígenas en Australia) en movimiento:

\footnotetext{
Siempre y cuando tenga una conexión a Internet decente, puedo hacer todo lo que necesito desde aquí. Puedo alquilar una habitación o apartamento para un mes y gastar menos de lo que gastaría en una semana en Perth. Además, puedo hacer senderismo, yoga, recibir enseñanzas [budistas], comer fuera y conocer gente interesante. Puedo trabajar cuando me da la gana, voy a mi propio ritmo. Por lo que respecta a hacer un doctorado, se trata de un muy buen estilo de vida.
} 
El acceso a Internet y un ordenador portátil permiten a gente como Anna mantener la continuidad con el trabajo y la vida "en casa" desde la distancia. Jason, un científico medioambiental en un descanso de tres meses de su trabajo en Camboya, que lo llevaría en un tortuoso viaje por la India, Nepal, Turquía, Inglaterra y finalmente de vuelta a Phenom Phen, viajaba con un ordenador portátil en el que trabajaba en un informe para el gobierno camboyano. Durante nuestra estancia en Pokhara, algunos días solo salía de la casa de huéspedes donde nos alojábamos para comer y explicaba: "Realmente tengo que terminar esta cosa [el informe]". Dado que su contrato de dos años en Camboya concluía no mucho tiempo después de volver de su estancia global, también estaba buscando trabajo y enviando curricula por Internet. Buscar posibilidades futuras online durante el viaje era otra práctica común y digna de mención entre los viajeros que llevaban tecnologías móviles. Muchos se encontraban en un periodo de transición en sus respectivos empleos, ya habían sido despedidos o estaban terminando contrato o simplemente dejando sus trabajos. Otros habían terminado recientemente estudios universitarios o habían decidido hacer grandes cambios en su vida. Las tecnologías móviles aparecen así como parte integrante de las vidas en movimiento (incluida la vida laboral) ${ }^{42}$.

Las trayectorias narrativas de estos estilos de vida tecnológicos y móviles, ejemplificados por los "nómadas globales", se caracterizan por ser cada vez más improvisadas, contingentes, no lineales, individualizadas y ensambladas "sobre la marcha". A medida que las identidades se vuelven "proyectos reflexivos"43 y las biografias dejan de estar predeterminadas por la sociedad, los individuos se enfrentan a una selección de elementos a negociar mucho más amplia y que se da también en el ámbito laboral. ${ }^{44}$ Las condiciones globales de la modernidad tardía ofrecen un alto nivel de flexibilidad, como ilustran aquellos que trabajan y viajan a la vez -o trabajan desde casa-, pero esta flexibilidad tiene un precio. Al transformarse los contratos en pequeños paquetes espaciales, temporales y contractuales, hay una falta de seguridad en el empleo y un mayor riesgo, independientemente de las cualificaciones y de la posición social. $^{45}$

Se ha sugerido, sin cuantificar, que existe una tendencia actual a tener estilos de vida individualizados, caracterizados entre otras cosas por tenues compromisos con los lugares de trabajo, así como por las relaciones y disposiciones orientadas más a moverse que a asentarse. Manifestando una "fobia al compromiso" 46 , endémica a la "nueva cultura del capitalismo", Sennet llega a decir que "solo un determinado tipo de ser humano puede prosperar en condiciones sociales inestables y fragmentarias" y se pregunta "¿qué valores y prácticas pueden mantener unidas a la gente y las instituciones que viven fragmentadas?" ${ }^{47}$. En otras palabras, a medida que los sujetos y las organizaciones sociales y móviles son cada vez más dispersos, efímeros e intercolocados, ¿qué tipo de ethos vamos a habitar? En la conclusión presentaremos algunas sugerencias.

\footnotetext{
${ }^{42}$ Fabian, 2002; Ortner, 2001; Said, 1978.

${ }^{43}$ Elliott \& Urry, 2010.

${ }^{44}$ Bauman, 2000 y 2008; Beck \& Beck-Gernsheim, 2002.

${ }^{45}$ Ver Beck \& Beck-Gernsheim, 2002.

${ }^{46}$ Bauman, 2008, p. 15.

47 Sennet, 2006, p. 3.
} 


\section{Organizar y decidir en movimiento}

El cambiar billetes de avión e itinerarios de viaje, así como indagar posibles destinos futuros, son otras tareas que ocupaban parte del tiempo que los viajeros pasaban online, especialmente para aquellos con viajes relativamente largos y/o alrededor del mundo. Muchos viajeros independientes estructuran de manera poco rígida sus viajes y siguen itinerarios flexibles y a menudo improvisados. Los billetes aéreos se reservan online y se modifican con frecuencia en base a una serie de factores y decisiones que surgen sobre la marcha. Los lugares son visitados por diversos períodos de tiempo, que se determinan en gran medida en función de las respuestas afectivas y sentimientos que los viajeros sienten respecto a los "nuevos" lugares en que se encuentran. Muchos viajeros explicaron que ellos no sabían qué esperar de los lugares que habían planeado visitar y decidirían quedarse o irse después de pasar unos días y ver qué "sensaciones" les suscitabanestos lugares. Vi a algunos viajeros llegar a Dharamsala, echar un vistazo e irse al día siguiente. Otros llegaban y pasaban un mes o más. Estas decisiones ad hoc parecían depender en gran medida de la percepción situacional y de lo que los viajeros describen como la "energía" o "vibraciones" que los lugares desprenden.

Aunque muchos viajeros mantienen sus viajes relativamente abiertos y flexibles, tener determinadas intenciones y el objetivo de ir a ciertos destinos previamente elegidos también resultaba algo significante. Estos objetivos se refieren a lugares específicos que se quiere visitar, un determinado evento, como un retiro de yoga o meditación, o un cierto itinerario. Muchas veces estos objetivos constituyen los puntos focales de trayectos más amplios y añaden una cualidad de peregrinación a lo que a veces parecía más un nomádico deambular. Y, sin embargo, son las tecnologías móviles las que permiten a los viajeros ampliar la posibilidad de reordenar los itinerarios, investigar otros destinos y reorientar los viajes entre y alrededor de estas otras actividades más concretas.

\section{Los viajes globales y la voluntad de (des)conectar}

Además de reorganizar rutas de viaje con la ayuda de medios de comunicación móviles, se dedicaba mucho tiempo a editar, presentar y ordenar fotografías, vídeos o documentos, así como a ver películas descargadas y escuchar música o podcasts. Viajar con "movilidades miniaturizadas" en un mundo digital en red significa que uno puede contactar y ser contactado, responder y ser respondido, y es responsable de "mantenerse en contacto". Como Casey ${ }^{48}$ señala, el llevar dispositivos de comunicación digital fomenta la "ilusión" de que uno está siempre disponible para la comunicación. Viajando con mi portátil y mi iPhone, sentí una extraña compulsión a revisar mi correo electrónico regularmente y mantener a mis amigos, familia $\mathrm{y}$ supervisores informados de todo, a menudo a través de fotos a veces tomadas ese mismo día. Traté de encontrar los momentos adecuados para conectarme por Skype con mi pareja en Nueva Zelanda, que estaba pasando por un período difícil y necesitaba más apoyo de lo que podía ofrecer en la distancia, con o sin medios de comunicación móviles. De hecho, hacia la mitad de mis cuatro meses de estancia, se

${ }^{48}$ Casey, 2012. 
molestó mucho conmigo debido a la insuficiente comunicación que manteníamos y nuestra relación casi llegó a su fin por este motivo.

Parece que, en un mundo tan hiper-conectado, prácticamente no hay excusa para no estar en contacto. Larissa Hjorth ${ }^{49}$ captura las paradojas de viajar con una "correa electrónica" cuando escribe que "el teléfono móvil nos hace 'libres' para vagar geográficamente, pero su función siempre activa significa que siempre estamos, aparentemente, disponibles". Lo que mi compañera no parecía ver (o estar dispuesta a aceptar) es que estar "siempre disponible" en Nepal o la India es mucho más complicado que en Nueva Zelanda. No solo había que considerar la diferencia horaria para las llamadas de Skype, sino también el hecho de que las redes locales de Internet son a menudo demasiado lentas o se vuelven repentinamente inaccesibles, dados los frecuentes cortes de energía. Por otra parte, a veces yo estaba en movimiento, viajando en autobuses o trenes durante días y días. $\mathrm{O}$ me encontraba en lugares remotos con poca o ninguna posibilidad de acceder a Internet, como fue el caso en Sikkim. En otras ocasiones, estaba demasiado enfermo para hacer nada, y mucho menos buscar una conexión a Internet. Sabiendo que mis seres queridos, especialmente mi compañera, estaban esperando tener noticias de mí, estos periodos de desconexión o indisponibilidad temporal me originaban un sentimiento de ansiedad e incluso culpa, que impactaba y alteraba mis experiencias inter-(des)ubicadas. Si no contactaba durante más de una semana, me encontraba en un estado de preocupación por la gente y los mensajes que estaba descuidando, por mi buzón de correo electrónico que sin duda se estaba llenando, aguardando que lo abriese y ofreciese respuestas.

Me di cuenta de que no estaba solo en la negociación de las aparentes paradojas que presenta el experimentar lugares con tecnologías móviles. Al preguntar a otros viajeros cómo hacían frente a estas circunstancias, varios explicaron que sentían diferentes grados de presión para mantenerse en contacto. Este era el caso, sobre todo, después de intervalos de desconectividad relativamente prolongada, como al cabo de varios días de caminata, yoga o meditación, o después de estar en un lugar remoto, con acceso limitado o directamente sin acceso a Internet. El hecho de que estos viajeros y yo pensáramos en esto, nos preocupáramos y sintiésemos que estábamos "fuera de contacto" durante dichos intervalos de "desconexión" resultaba revelador en dos niveles. En primer lugar, simplemente muestra cuan arraigado, habitual y omnipresente resulta el uso de los medios de comunicación en la vida contemporánea. En segundo lugar me demostró que, incluso cuando los medios de comunicación móviles no están disponibles o en uso, pueden permanecer presentes a nivel inconsciente. Este fenómeno refiere a lo que Urry y Elliot ${ }^{50}$ llaman el "inconsciente tecnológico", un reino de trasfondo en el que se negocian relaciones sociales mediadas digitalmente y que implican un alto grado de ausencia, distancia y desconexión. La idea de que hay un inconsciente tecnológico en funcionamiento implica que, en la era de los sistemas mundiales en red en la que las tecnologías digitales se entrelazan corporalmente con seres móviles, no parece haber ningún lugar donde una persona pueda estar real y verdaderamente "ahí fuera", "lejos de todo", ni siquiera en el interior de la cordillera del Himalaya.

\footnotetext{
${ }^{49}$ Hjorth, 2012, p. 141.

${ }^{50}$ Urry \& Elliot, 2010, p. 10.
} 


\section{A la deriva dentro, fuera y entre lugares}

Incluso si no hay acceso a Internet disponible, el viajar con dispositivos móviles permite que nuestras bibliotecas digitales de fotos, música y demás nos acompañen. Como Urry y Elliot ${ }^{51}$ observan, las tecnologías móviles permiten a los usuarios acceder y depositar afectos, humores y disposiciones dentro de tecno-objetos. Los procesos de almacenamiento y recuperación de afectos digitales alteran la experiencia del viajar y "generan nuevas formas de la identidad que están menos ligadas a localidades fijas, patrones regulares o arraigadas tradiciones culturales" ${ }^{52}$. Las tecnologías móviles facilitan lo que estos autores denominan "personalidad portátil" "53: una especie de puente psicológico o superación de la fragmentación espacial que se da en condiciones de movilidad intensivas. Esta personalidad transportable es similar a la noción anterior de Raymond Williams ${ }^{54}$ de "privatización móvil", a la que Williams describía como el modo en que las tecnologías domésticas, como la televisión y el teléfono, ayudaban a difuminar los límites entre aquí y allá, en casa o fuera, lo vivido y lo imaginado, lo local y lo global. Como señala Hjorth ${ }^{55}$, las "tecnologías móviles [en particular] han sido vehículos importantes en la extensión de las prácticas copresenciales del lugar".

La siguiente historia de un largo viaje en autobús que hice por el centro de Nepal ilustra cómo el viajar con medios móviles altera la experiencia del viajar. Una mañana temprano partí de Katmandú hacia Pokhara en el viaje en autobús más agitado de mi vida (el mismo que el bien viajado Jason describió como "suave como un avión"). Yo era uno de los seis extranjeros en ese desvencijado trasto de veinte plazas. El resto eran locales. Me senté en la parte de atrás porque toda la fila estaba vacía, lo que me permitiría estirarme tranquilo en lo que sería un viaje de ocho horas. Pronto aprendí, sin embargo, que la razón por la que nadie se sienta en la parte de atrás es que los amortiguadores de los autobuses nepalíes son básicamente inexistentes, lo que significa que cada bache y agujero en la carretera -y los caminos en Nepal están llenos de baches y agujeros- es vivido en toda su plenitud y violencia. Esto le deja a uno con la espalda tocada y el trasero dolorido $-\mathrm{y}$ así estaría yo cuando finalmente nos detuviéramos en Pokhara-. No había nada que hacer con los baches, así que me contenté con la novedad que suponía estar en Nepal y contemplar el paisaje durante el trayecto.

Después de una hora o así, habiendo ya dejado atrás el valle de Katmandú y moviéndonos lentamente por un sinuoso camino a través de una serie de valles altos, saqué mi iPhone y los auriculares con cancelación de ruido. Tenía dudas sobre ello, como si el conectarme a este dispositivo fuese a corromper, interrumpir o poner en peligro la pureza y autenticidad de la experiencia de estar en Nepal. Como si fuese a debilitar mi capacidad de percepción corporal y observación. Después de todo, prestar atención a los fenómenos o conectarse también significa desconectarse de los demás. Sin embargo, con todos los golpes y baches violentos, junto con la música india a todo volumen que salía de los altavoces baratos, el autobús era increíblemente ruidoso.

\footnotetext{
${ }^{51}$ Urry \& Elliot, 2010.

${ }^{52}$ Ibid, p. 6.

${ }^{53}$ Ibid, p. 33.

${ }^{54}$ Williams, 1975.

${ }^{55}$ Hjorth, 2012, p. 141.
} 
Durante aproximadamente una hora, la novedad de la situación resultaba lo suficientemente interesante y "auténtica", pero finalmente pasé a sentirme aburrido y simplemente incómodo. El aire estaba brumoso, por lo que las vistas del Himalaya no resultaban tan espectaculares como esperaba, y las agudas voces femeninas me taladraban los oídos. Pensé en entablar conversación con mis compañeros de viaje, pero la gente parecía indiferente a mi presencia. Supongo que para ellos no era más que otro turista que pasaba a través de su patio trasero. En lo que se refiere a los demás pasajeros extranjeros, los seis llevaban auriculares que, entre otras cosas, funcionaban esencialmente como una señal de "no molestar".

Teniendo en cuenta que faltaban todavía unas seis o siete horas de este largo y agotador viaje, cogí mi iPhone. Al ponerme los auriculares con cancelación de ruido, mi atención pronto derivó hacia otros lugares y realidades. No obstante, los baches del camino, ahora silenciosos, el dolor en la espalda y en la parte inferior, y mi campo visual se encargaban de recordarme que mi cuerpo todavía estaba en el autobús. Y, sin embargo, ¿qué tipo de "estar aquí" o "estar en" era esto? Escuché una serie de podcasts que había descargado antes de partir hacia Nepal. La primera era de actualidad y cubría principalmente el levantamiento de la primavera árabe, que en ese momento estaba ganando atención, gracias en gran parte a la utilización de las tecnologías móviles y las redes sociales, especialmente Facebook y Twitter. Luego escuché un podcast de arte y cultura del New York Times y una reseña de libros producida por una estación de radio en Los Angeles. Más tarde estuve escuchando algo de música, seguido de dos conferencias de un curso de la Universidad de Berkeley sobre historia de la antropología, que me había descargado desde el programa iTunes U. Mientras miraba a través de la ventana las montañas áridas, con terrazas de arroz y otros cultivos, y la colección ocasional de casas de campo y cabañas rústicas, el Profesor Joyce daba una conferencia sobre las nociones de Durkheim de la solidaridad mecánica y orgánica. "¿Qué tipo de solidaridad existía entre la gente en este autobús?", me pregunté. No podía hablar por los nepalíes locales (ni con ellos, ya que mi nepalí se limita a solo una pocas frases y, de todos modos, no parecían interesados en las formas de vida de los turistas con las que compartían el autobús). Sentado en mi asiento con mis auriculares puestos, sentí una sensación de vacío. "La paradoja de la conexión global... parece conducir a una mayor y mayor desconexión" fueron las palabras que escribí en mi cuaderno de notas después del largo viaje en autobús.

En el ensayo de Augé, "Paisajes planetarios",56, el antropólogo francés que aproximadamente veinte años antes propuso una teoría de los "no-lugares" sugiere que lo que se requiere en la actualidad es cuestionar los tipos de relaciones creadas por las tecnologías de comunicación. Al reflexionar sobre las paradojas de las comunicaciones virtuales, se pregunta por qué la gente sigue sintiéndose tan sola en un mundo que se define como "conectado". Augé revisa su concepto de "no-lugares", que hace referencia a "espacios de comunicación, consumo y circulación... espacios de temporalidad y transitoriedad, espacios que no fueron marcados por ningún tipo de relaciones sociales, historia compartida o signos de identificación colectiva", como aeropuertos, autopistas y centros comerciales 57 . En esencia, los "no lugares" eran la antítesis de los pueblos africanos tradicionales que Augé había estudiado previamente.

\footnotetext{
${ }^{56}$ Augé, 2008.

${ }^{57}$ Ibid, p. 275.
} 
En la era de las comunicaciones en red a nivel mundial, sin embargo, él y otros antropólogos empiezan a ver las limitaciones del lugar/no lugar binario. Más bien reconocen que los lugares y los lazos sociales son experimentados y formados en todo tipo de entornos, solo que de diferentes maneras a las usadas en tiempos anteriores, menos tecnologizados, móviles e interconectados. En otras palabras, los lugares no simplemente desaparecen o se convierten en no-lugares, sino que se alteran, reconfiguran y experimentan en diferentes y particulares formas.

\section{Residir en el des-distanciamiento y viajar en la era de la "Gestell Digital"}

Como se ha descrito antes, el uso de Internet y las tecnologías móviles se incorporó en los ritmos diarios, prácticas corpóreas y comportamientos de los viajeros que, a pesar de estar físicamente distantes, seguían conectados con las realidades de sus vidas cotidianas, parejas y proyectos "en casa". Esta capacidad y propensión a permanecer conectados o "mantenerse en contacto" puede estar relacionada no solo con la necesidad humana de mantener los vínculos sociales, sino también con las reflexiones de Heidegger ${ }^{58}$ sobre la orientación espacial del ser humano como Dasein más fundamental. Heidegger observa cómo "una tendencia fundamental hacia la cercanía se encuentra en Dasein" "59 y señala dos características definitorias de Dasein como des-distanciamiento (Ent-fernung) y direccionalidad (Ausrichtung).

Des-distanciamiento significa hacer desaparecer la distancia, haciendo que el estar a distancia de algo desaparezca, acercándolo. Dasein es esencialmente des-distanciamiento. ${ }^{60}$

Como el ser-en-el-mundo, Dasein habita fundamentalmente en el des-distanciamiento. (...) Como el ser-en que des-distancia, Dasein tiene al mismo tiempo el carácter de direccionalidad. $^{61}$

El des-distanciamiento direccional y "acercador" del Dasein se intensifica y amplia por el uso de las tecnologías de información y comunicación en un orden mundial digital en red. Escribiendo mucho antes de la revolución digital y la "bomba de información"62 que caracteriza el principio del siglo XXI, Heidegger observa el creciente ritmo y la compresión espacio-temporal tecnológica que ocurre en la modernidad, así como las implicaciones que esto tiene para las experiencias inmediatas del lugar:

Todos los tipos de aumento de la velocidad con los que estamos más o menos obligados a ir, empujan a superar la distancia. Con la radio, por ejemplo, el Dasein está produciendo hoy un des-distanciamiento del "mundo", por el camino de una ampliación y destrucción del mundo cotidiano que nos rodea, que es imprevisible en su significado para el Dasein. ${ }^{63}$

Paradójicamente, el des-distanciamiento o el acercamiento de mundos distantes generado por la comunicación digital en red parece, simultáneamente, alejarnos de los

\footnotetext{
${ }^{58}$ Heidegger, 1996.

${ }^{59}$ Ibid, p. 98.

${ }^{60}$ Ibid, p. 97-98.

${ }^{61}$ Ibid, p. 100.

${ }^{62}$ Virilio, 2005.

${ }^{63}$ Heidegger, 1996, p. 98.
} 
contextos de la vida cotidiana local. La aparente paradoja se profundiza cuando consideramos las aventuras que la mayoría de viajeros en el Himalaya afirman estar buscando, pues, como observa Georg Simmel ${ }^{64}$, el "sentido profundo" de una aventura está dado por el hecho de que ocurre "fuera de la continuidad normal de esta vida" y en contraste con los "enlaces vitales conectados". Y, sin embargo, mediante el acceso a Internet, manteniéndose en contacto y haciendo futuros planes de viaje y vitales mientras se está en movimiento, la vida relacionada con el hogar continuó para los viajeros en Nepal y la India. Mientras que las peregrinaciones, aventuras e incluso las vacaciones de turismo se han asociado a las inversiones rituales, las formas del viajar tecnológicamente mediadas problematizan la clásica dicotomía estructuraantiestructura y las nociones de "liminalidad". En contraste con épocas anteriores, los viajes en el siglo XXI se convierten en un evento que ya no tiene un lugar real que sea verdaderamente un "ahí fuera", sino una multitud de aquís, allís y en lugares intermedios. Los viajeros liminales ya no son "muertos para el mundo". ${ }^{65}$ En lugar de ello, gracias a las tecnologías móviles que llevan, están disponibles para contactar y ser contactados, para responder y ser respondidos, al tiempo que son responsables de mantener el contacto. Todavía están "entre lo uno y lo otro", pero no en el estricto sentido de los roles sociales de Turner, sino entre los lugares y actividades de transformación en las que permanecen involucrados en y desde la distancia (física). ${ }^{66}$ Esto se debe a que los medios de comunicación móviles cumplen la función de puente, uniendo o des-distanciando el espacio y el tiempo entre varios lugares. Como la extensión, el des-distanciamiento y el acercamiento son características del Dasein; las tecnologías digitales simplemente aumentan lo que ya es una orientación espacial común de nuestro ser-en-el-mundo. McLuhan llegó a ideas similares acerca de cómo diferentes tecnologías transforman la experiencia espacio-temporal y, por lo tanto, las formas de conocer, actuar y experimentar el mundo. Al igual que Heidegger, ofrece un recuento histórico de la aniquilación tecnológica del tiempo y el espacio:

Durante las edades mecánicas ampliamos nuestros cuerpos en el espacio. Hoy, después de más de un siglo de tecnología eléctrica, hemos extendido nuestro sistema nervioso central en sí mismo en un abrazo global, aboliendo el espacio y el tiempo en lo que se refiere a nuestro planeta. (...) Como si se hubiera contraído eléctricamente, el mundo no es más que una aldea. ${ }^{67}$

Dos importantes ideas vale la pena resaltar aquí. En primer lugar está la idea de la tecnología como una extensión del cuerpo y los sentidos. Como la corporalización (embodiment) es siempre ya "instrumental" y "equipamental", existe una relación recíproca entre los cuerpos y las tecnologías. Las tecnologías, según Haraway ${ }^{68}$, no son mediaciones o cosas que se interponen entre nosotros y el mundo, sino más bien son "órganos", "socios de pleno derecho" que se "introducen en la carne". Está, pues, de acuerdo con el compromiso básico de Don Ihde ${ }^{69}$ de que, en la medida en que la tecnología sea utilizada o empleada por los agentes humanos, los agentes humanos también son utilizados y empleados por la tecnología. Partiendo del supuesto que el cuerpo vivo y emplazado es la "base" o medio para todas las experiencias, incluyendo las movilidades virtuales o imaginativas, el uso de tecnologías no es algo incorpóreo.

\footnotetext{
${ }^{64}$ Simmel, 1997, p. 224.

${ }^{65}$ Turner, 1992.

${ }^{66}$ Küpers, 2011.

${ }^{67}$ McLuhan 2008, p. 12-13.

${ }^{68}$ Haraway, 2008, p. 249.

${ }^{69}$ Ihde, 2001.
} 
Esto no quiere decir que la tecnología y los espacios virtuales sean neutrales, pues transforman y condicionan nuestras experiencias del lugar, el yo y los demás, de manera profunda. Como Urry y Elliot ${ }^{70}$ apuntan, los seres individuales no solo "emplean" o activan las tecnologías digitales en la vida cotidiana. Por el contrario, en condiciones de movilidades intensivas, el yo se convierte en múltiples capas y es reformado por la influencia de las redes tecnológicas.

$\mathrm{Y}$, sin embargo, esto no quiere decir que la tecnología tiene que ser vista necesariamente como algo que aliena a los humanos de una supuesta naturaleza o de la relación original o auténtica con el "lugar". Continuos y dinámicos, históricos y siempre en formación, los acoplamientos o repliegues "cuerpo-tecnología-mundo" evolucionan con y contribuyen a una continua reinvención de lo humano. Si la tecnología es una "extensión del hombre", y el ser humano es imaginado como un conjunto de órganos con la tecnología como la suma de las prótesis, el homo sapiens o animal racional se convertiría en "animal tecnológico", siempre trabajando en la ampliación de su radio de acción y la optimización de sus órganos artificiales ${ }^{71}$. El antropólogo filosófico Plessner ya había articulado una posición similar en el siglo $\mathrm{XX}$, cuando sugirió que, en tanto que "excéntricamente posicionados", los seres humanos son "artificiales por naturaleza" 72 .

\section{Gestell: ser en-marcado}

El que las tecnologías móviles alteren y reconfiguren las relaciones entre las experiencias de lugar, así como del yo y de los otros, en el contexto de los viajes, es de hecho parte de una tendencia histórica mucho más amplia, la de la "tecnologización" de la vida en general. Es útil pensar en este tipo de condiciones cuando se considera la noción de encuadre (Gestell ) de Heidegger. Según Heidegger, Gestell, que significa literalmente "encuadre" o "marco", no es algo tangible, sino más bien un "concepto" y una forma de $\operatorname{ser}^{73}$. Heidegger apunta a la forma particular en que el mundo se revela a los seres humanos a través de la tecnología como una cuestión ontológica, que no puede ser reducida a consideraciones éticas o epistemológicas. Señala que, en la modernidad, ya nos encontramos en un mundo tecnológicamente enmarcado, un hecho que tanto abre como limita nuestros horizontes.

La Gestell media una vista que todo lo abarca y un enfoque para el uso de la tecnología, no (solo) como un medio para un fin, ni como algo tecnológico, sino más bien como un modo de existencia (humana). Como tal, es una postura hacia al mundo que reúne y divulga. Esta postura organiza y transforma todo en un orden calculable e instrumentalizado que Heidegger llama una "reserva latente" (Bestand). El mayor peligro de los modos contemporáneos móviles del "residir viajando" en la edad de la Gestell digital es que, a través de la mediatización en curso y la hiper-conectividad de la sociedad móvil y en red $^{75}$, el mundo llega a parecerse a una reserva en pie en la que todo y todos los lugares parecen al alcance. A pesar de esta apariencia, la movilidad

\footnotetext{
${ }^{70}$ Urry \& Elliot, 2010.

${ }^{71}$ Ihde, 2001.

${ }^{72}$ Plessner, [1928] 1975.

${ }^{73}$ Heidegger, 1978..

${ }^{74}$ Clifford, 1997, p. 108.

${ }^{75}$ Castells, 2000.
} 
global llega a costa de los entornos naturales y las economías y culturas locales, por no hablar de las experiencias inter- e intra-personales. Ser enmarcado en el modo de "reserva en pie" es solo ser responsable ante criterios instrumentales y ante la lógica del poder y la dominación ${ }^{76}$, e incluso los seres humanos (los viajeros) son "objetivados", ya que se convierten en un conjunto calculable y reducible de patrones pre-programados e in-formatizados y de múltiples "redes de trabajo" gobernadas por la lógica valor-uso.

A través de sus poderes reveladores, la tecnología moderna y sus dispositivos tienen una tendencia a liberar, transformar, almacenar y distribuir los recursos que la naturaleza (y la cultura) tienen para ofrecer en una matriz contextual de relaciones. Al mismo tiempo, también nos hace reductivos a nivel ontológico para ver toda la realidad -incluyendo a los seres humanos- como meros recursos dispuestos, sin restricciones, para la eficiencia máxima, que se utilizan y controlan, como bienes explotados y desprovistos de cualquier condición intrínseca y significado.

El mayor peligro del "destinar" (Geschick) la tecnología moderna como manifestación del pensamiento calculador no (solo) se encuentra en dañar el medio ambiente o destruir culturas. El verdadero peligro es que la comprensión tecnológica del mundo se convierte en la única manera de relacionarse con las cosas y con los demás seres humanos. Por otra parte, y al mismo tiempo, esta operación permanece oculta, lo que indica el hecho mismo de que la tecnología "desenmascara" el ser de una manera particular, limitada y exclusiva. La amenaza real es que todo lo que aparece como un problema o solución tecnológica no puede únicamente estar basado en la tecnología, por lo que el pensamiento calculador se acepta como la única forma posible de pensar. Esto implica que, por ejemplo, la naturaleza, la política, la cultura y los valores se convierten en "objetos" explotables para la gobernabilidad, la producción, etc, así como para la organización y el consumo, incluyendo el viaje tecno-movilizado.

Un mundo hiper-mediado, como McLuhan observó ya en la década de 1960, convierte el mundo en una aldea en la que todo y todas las partes parecen accesibles. Al acceder a la página web de Lonely Planet, por ejemplo, el mundo nos es revelado como un almacén o "reserva en pie" de lugares donde ir, jugar, tener aventuras o, si se quiere, recolectar y consumir. Desde una interpretación crítica, esto podría leerse como la manifestación de la omnipresente "voluntad de consumir" en la modernidad tardía. ${ }^{77}$

Para muchos viajeros, Nepal y la India representan lugares con cualidades únicas, tales como la autenticidad, la espiritualidad y la "naturaleza" pura, salvaje. Sin embargo, en la práctica, aparecían como simples telones de fondo intercambiables y consumibles lugares en los que se podía entrar y salir como se ha descrito antes. Esta orientación opcional y consumista parece ser una característica clave de la actitud tecnológica contemporánea y el mundo digital enmarcado. Las tecnologías móviles y la conectividad en red permiten una vida siempre en movimiento, permitiendo a la gente no residir genuinamente aquí y ahora, sino estar en movimiento constante, en un interlugar global que parece estar aquí, allí y en ninguna parte al mismo tiempo.

\footnotetext{
${ }^{76}$ Cooper, 2002.

${ }^{77}$ Baudrillard, 1997; Bauman, 2008; MacCannell, 2011; Urry, 2011.
} 
Sin embargo, críticamente podemos preguntar si el dominio de la tecnología moderna no es, precisamente, la última consecuencia de la forma en que la metafísica que ahora procesa tecnológicamente el nihilismo ha interpretado el mundo, una incansable y firme "voluntad de voluntad". Tal interpretación transforma tanto la tecnología moderna como la metafísica de la Gestell en cosas homogéneas y unidimensionales. $\mathrm{Su}$ diversidad aparente sería entonces solo superficial. Esta posición radical evitaría discriminar entre diferentes tecnologías y diferentes usos de los seres humanos de hoy en día. Frente al predominio generalizado del enmarcar, persiste el reto de desarrollar formas creativas para salir del nihilismo tecnológico y cultivar reflexiones éticopolíticas, así como actitudes receptivas y responsables.

\section{Implicación y conclusión}

En este trabajo, hemos mostrado líneas de vuelo fenomenológicas y hallazgos empíricos para contribuir a una comprensión procesual de los viajeros, de sus viajes y de la incursión sistémica como evento inter-relacional e inter-puesto del (pasar a) ser. Los resultados del trabajo de campo etnográfico revelaron prácticas corporales y corporizadas, así como dinámicas del viaje nómada, dis- y entre-localizadas. Como se ha descrito, estos viajes transicionales son formas penetrantes de viajar y vivir enmarcadas digitalmente.

En principio, los viajes mediados por la tecnología parecían la antítesis de las experiencias corporales del lugar en las que se centra el viajar. El entender los lugares como procesos relacionales nos permite ver cómo los medios móviles se incorporan a los ritmos espacio-temporales de lugares específicos, contribuyendo a su contingente "improvisación" y negociación. Los viajeros llevaban a cabo sus actuaciones particulares en el lugar con sus tecnologías incorporadas, que sirven como extensiones de su presencia corporal. Esto confirma que, efectivamente, se ha producido una "dispersión" de las prácticas tecnológicas hacia otros ámbitos de la vida: del trabajo a casa, la vida pública y ahora incluso a viajar a lugares remotos.

El uso de las tecnologías móviles era, de hecho, parte significativa de estos viajes con sus múltiples etapas, fases y ritmos. Pero otras fases giraban en torno al desconectar, desacelerarse y genuina y sensiblemente experimentar el lugar y la vida local, así como hacer lo propio con uno mismo y los demás. En las zonas periféricas, donde el acceso a Internet era más limitado, o durante ciertas fases del viaje-como por ejemplo durante los retiros de yoga y meditación o durante excursiones de montaña de varios días-, el uso de la tecnología móvil era menos frecuente. Siguiendo a $\mathrm{Bey}^{78}$, estas esferas pueden ser interpretadas como "zonas temporalmente autónomas". Liminalmente, estas pueden entonces ser zonas de contacto periféricas, en la "frontera",79 como orden relativamente descentralizado, donde seres humanos, orientaciones, culturas y formas de vida dispares pueden reunirse e invitar al aprendizaje y la imaginación, sin la fuerza constrictora proveniente de la fijación del centro $^{80}$.

\footnotetext{
${ }^{78}$ Bey, 2003.

${ }^{79} \mathrm{~N}$. del traductor: Aquí los autores, al escribir "b-order" hacen un juego de palabras. "Border" significa borde, frontera, pero al intercalar el guión se puede interpretar también como un orden "b" o secundario. ${ }^{80}$ Conroy, 2004.
} 
Nuestros resultados nos invitan a considerar posibles implicaciones y perspectivas de investigación. Aquí sugerimos únicamente algunas ideas de formas más sensibles y responsables para el viajar y la vida inter-localizada, y proponemos un ethos de desprendimiento comprometido (Gelassenheit) como práctica inter-localizadora.

Si los lugares para el viaje tecno-nómada continúan siendo claves para una participación corpórea con los mundos fenoménicos, ecológicos, individuales, sociales y culturales a través de lo cuales uno se mueve, entonces, aquello que los viajeros saben y hacen también está formado por las relaciones con su localización y posición. De allí la calidad de una atención que se da al vivir en lugares y el nuevo compromiso consciente hacia ellos que surge a través de una "orientación sensible al lugar y consciente del lugar" ${ }^{\prime 1}$. El ser relacionalmente-responsable considera cómo el cambio de circunstancias o situaciones de lugar al viajar o moverse "pide" o motiva respuestas espontáneas y adecuadas ${ }^{82}$.

Cultivar un sentido de respuesta incluye una responsabilidad corpórea y sensible, además de ciertas formas de direccionalidad que procesen correspondencias o respuestas adecuadas. Los viajeros receptivos a la espontaneidad, como "visitantes conscientes" ${ }^{\prime 83}$ y (co)rrespondientes, podrían practicar una relación perceptiva y atenta, así como una sintonía no-objetivizante con el entorno, apreciando las cualidades sociomateriales y culturales y las comunidades receptoras, lo que conduciría a una orientación sensible y responsable más integral ${ }^{84}$. Los eco-viajeros responsables podrían realizar su visita con sensibilidad hacia el medio ambiente y la gente local ${ }^{85}, \mathrm{y}$ probablemente serían más bio-esféricos, ya que percibirían la naturaleza como un valor intrínseco y que, por tanto, necesita ser protegido ${ }^{86}$. Es más, el turismo educativo sensible, incluso podría ser un medio para el aprendizaje de la sabiduría ${ }^{87}$.

Entre el orden y lo extraordinario, emerge una respuesta co-creativa y productiva; de hecho, nace, en el acto mismo de responderse a sí misma, una relación colocada mutuamente entre "respondientes" y "correspondientes" humanos poseedores de una apertura receptiva. Los viajeros, en tanto que "respondientes", creadores y co-autores, ya compartían sentimientos corpóreos, pensamientos y prácticas que surgían de circunstancias conjuntas. Las actividades en movimiento que responden de esta manera son así reveladas como una interacción resonante entre las "co-intenciones" (inter-)subjetivas y la rebeldía y la inherente naturaleza sensorial de los lugares, ya mediada e influenciada por la cultura y las socio-materialidades involucradas. Permitir que una respuesta corpórea suceda ayuda a que surjan movimientos y posibilidades imprevisibles, incluyendo formas creativas, "heterotópicas" 88 , de la inter-colocación y una orientación receptiva-responsable más integral ${ }^{89}$.

\footnotetext{
${ }^{81}$ Gruenewald, 2003; Cameron et al., 2004.

${ }^{82}$ Goessling et al., 2012.

${ }^{83}$ Moscardo, 1996.

${ }^{84}$ Küpers, 2012.

${ }^{85}$ Tucker, 2001.

${ }^{86}$ Perkins \& Brown, 2012.

${ }^{87}$ Pitnam \& Broomhall, 2011; Nightingale, 2004.

${ }^{88}$ Foucault, 1998 [1984].

${ }^{89}$ Küpers, 2012.
} 
Las recolecciones en sintonía con el cuerpo, a través de nuestra motilidad corporal y los movimientos, los gestos y la conciencia sentida corporalmente, son cruciales para disfrutar de una apertura en la que los fenómenos puedan revelarse a sí mismos. Según Levin $^{90}$, a través de un retorno (que es en realidad un avance) hacia la comprensión ontológica en el trabajo de recolección y encarnación humana, podemos aprender a vivir y movernos adecuadamente en la Tierra. En particular, teniendo en cuenta la omnipresente "Gestell digital" de los modos tecnologizados de viajar y vivir, deberíamos exigir un comportamiento y un ethos comprometidos del dejarse llevar o Gelassenheit como práctica relacional de inter-locación. Este Gelassenheit -traducido como liberación, dejarse ir, serenidad, calma, desapego- se refiere a un ethos noobjetivador, una pasividad activa y permanente, una aceptación a través del dejarse llevar, lo que implica un abandono de las orientaciones de apropiación y representación habituales. En este dejar-ser de las cosas, el Dasein no intenta manipular, amaestrar u obligar a las cosas, sino que deja que las cosas estén en su naturaleza esencial. Es importante destacar que no es indiferencia o falta de interés por las cosas, sino más bien un "arrendamiento comprometido".

El entrar en un modo de dejar-ser se realiza a través de una espera y escucha receptiva, de un no-hacer más activo, en lugar de un negocio de la voluntad y el control del dominio. En concreto, se pasa de un modo de representación y cálculo meditativo, a través del presenciar, hacia relaciones más poéticas. Más aún, el cultivo de la liberación hacia las cosas y los fenómenos permite decir "sí" y "no" a la tecnología, y ver las cosas no solo de una manera técnica. De esta manera, se desalienta el consumo fácil o la orientación hacia la explotación sin sentido. Desarrollar una relación relativamente libre hacia la tecnología no significa aspirar a una vida libre de usos tecnológicos, sino llevar una vida que no está constantemente ordenada por ellos.

Como una relación auténtica y libre con la tecnología, Gelassenheit está abierto a la presencia y la "esencia" de la tecnología en uso, en tanto que interlocalizada en los viajes y la vida. Los viajeros sensibles y liberados pueden utilizar dispositivos técnicos $\mathrm{y}$, sin embargo, con el uso adecuado, también mantenerse libres de ellos, para poder así dejarlos de lado y seguir una forma estética de relacionarse menos instrumental, no dominante sino intrínseca.

Además, las tecnologías de la información y los medios de comunicación globales se pueden utilizar para promover y asegurar el viaje lento. Ayudan a dar a conocer diversas ofertas de turismo lento y facilitan el intercambio de experiencias, y, por lo tanto, también la descentralización de la industria turística, desde el control exterior hacia el empoderamiento y la inclusión locales ${ }^{91}$.

Reconsiderar los inter-lugares del viaje como eventos corpóreos y relacionales permite el acceso a las posibilidades de una orientación diferente. Si los viajes tecno-nómadas son misiones con re-orientaciones o re-interpretaciones, en las que cultivar y experimentar formas de lugar-respuesta y un ethos de Gelassenheit, pueden contribuir a reconfigurar la relación con el lugar, el emplazamiento, el tiempo y la identidad en nuestra era tecnológica móvil y movilizadora.

\footnotetext{
${ }^{90}$ Levin, 1985.

${ }^{91}$ Conway \& Timms, 2010 y 2012.
} 
Se espera que los resultados, las ideas y las discusiones planteadas aquí inviten a nuevas exploraciones e investigaciones sobre esferas nómadas del viaje tecnomediado, a embarcarse hacia lo desconocido, y que contribuyan a otras presencias, más sensibles -es decir alter-nativas-, tanto sostenibles como responsables en el futuro por venir.

\section{Bibliografía}

ANDERSON, B. \& HARRISON, P. Taking-place: non-representational theories and geography. Farnham, VT: Ashgate, 2010.

AUGÉ, M. Planetary Landscapes. In DEPARDON, R., VIRILIO, P. et al. Native Land: Stop Eject. Paris: Foundation Cartier pour l'Art Contemporain, 2010.

BACHELARD, G. The poetics of space (trad. JOLAS, M.). Boston: Beacon Press, 2008.

BAUDRILLARD, J. The Consumer Society: myths and structures. London: SAGE, 1997.

BAUMAN, Z. Liquid Modernity. Cambridge, UK: Polity Press, 2000.

BAUMAN, Z. The Art of Life. Cambrige, UK: Polity Press, 2008.

BECK, U. \& BECK-GERNSHEIM, E. Individualization: institutionalized individualism and its social and political consequences. London: Sage, 2002.

BECK, U. \& SZNAIDER, N. Unpacking cosmopolitanism for the social sciences: a research agenda. British Journal of Sociology, 2006, $\mathrm{n}^{\mathrm{o}}$ 57, p. 1-23.

BEY, H.T. The Temporary Autonomous Zone, Ontological Anarchy, Poetic Terrorism (segunda edición). Brooklyn, New York: Autonomedia, 2003.

BRUNER, E.M. Transformation of self in tourism. Annals of Tourism Research, 1991, vol. $18, \mathrm{n}^{\mathrm{o}} 2$, p. $238-250$.

CAMERON, J., MULLIGAN, M. \& WHEATHLEY, V. Building a Place-Responsive Society through Inclusive Local Projects and Networks. Local Environment, 2004, vol. $9, \mathrm{n}^{\mathrm{o}} 2$, p. 147-161.

CASEY, E.S. Getting back into place: toward a renewed understanding of the placeworld. Bloomington: Indiana University Press, 1993.

CASEY, E.S. Between Geography and Philosophy: What Does It Mean to $\mathrm{Be}$ in the Place-World? Annals of the Association of American Geographers, vol. 91, nº 4 68393.

CASEY, E.S. Going Wireless: disengaging the ethical life. In WILKEN, R. y GOGGIN G. Mobile Technology and Place. New York: Routledge, 2012, p. 175-180. 
CASTELLS, M. The Rise of the Network Society, The Information Age: Economy, Society and Culture vol. I. Cambridge, MA: Blackwell, 2000.

CLIFFORD, J. Routes: travel and translation in the late twentieth century. Cambridge, Mass.: Harvard University Press, 1997.

COHEN, E. Authenticity and commoditization in tourism. Annals of Tourism Research, 1988, vol. 15, no 3, p. 371-86.

CONROY, J. Betwixt and Between: the Liminal Imagination, Education and Democracy. New York: Peter Lang, 2004.

CONWAY, D. \& TIMMS, B. Re-branding alternative tourism in the Caribbean: The case for 'slow tourism'. Journal of Tourism and Hospitality Research, Special Issue, $2010, \mathrm{n}^{\mathrm{o}} 12$, p. $1-16$.

CONWAY D., BENJAMIN, TIMMS. Are slow travel and slow tourism misfits, compadres or different genres? Research Probe in Tourism Recreation Research, 2012, vol. 37, $\mathrm{n}^{\mathrm{o}} 1$, p. 71-76.

COOPER, S. Technoculture and critical theory: in the service of the machine? London: Routledge, 2002.

CRICK, M. Representations of International Tourism in the Social Sciences: Sun, Sex, Sights, Savings, and Servility. Annual Review of Anthropology, 1989, nº 18, p. 307-44.

DELEUZE, G. \& GUATTARI, F. A Thousand Plateaus: capitalism and schizophrenia. London: Continuum, 2004.

DREYFUS, H.L. Intelligence without representation - Merleau-Ponty's critique of mental representation: The relevance of phenomenology to scientific explanation. Phenomenology and the Cognitive Sciences, 2002, vol. 1, nº 4, p. 367-383.

DREYFUS, H.L. How Representational Cognitivism failed and is being replaced by Body/World Coupling. In LEIDLMAIR, K. After Cognitivism. Dordrecht, Heidelberg, New York, London: Springer: Springer Netherlands, 2009, p. 39-73.

ELLIOTT, A. \& URRY, J. Mobile lives. New York, NY: Routledge, 2010.

ERIKSEN, T. H. Tyranny of the Moment: Fast and Slow Time in the Information Age. London: Pluto Press, 2012.

FABIAN, J. Time and the Other: how anthropology makes its object. New York: Columbia University Press, 2002.

FOUCAULT. M. Different spaces. In FAUBION, J.D. (Ed.). Aesthetics, Method, and Epistemology: Essential Works of Foucault Volume 2. London: Penguin, 1998 [1984], p. $175-185$. 
GOESSLING, S.; SCOTT, D. \& HALL, M. Consumer behaviour and demand response of tourists to climate change. Annals of Tourism Research, 2012, vol. 39, $\mathrm{n}^{\circ}$ 1, p. 36-58.

GOODMAN, N. Ways of worldmaking. Hassocks, Eng.: Harvester Press, 1978.

GRUENEWALD, D.A. Foundations of place: a multidisciplinary framework for place-conscious education. American Educational Research Journal, 2003, vol. 40, $\mathrm{n}^{\mathrm{o}}$ 3, p. 619-654.

GUPTA, V. Sustainable tourism: learning from Indian religious traditions. International Journal of Contemporary Hospitality Management, 1999, vol. 11, $\mathrm{n}^{\mathrm{o}} 2$, p. 91-113.

GURUNG, D.B., SEELAND, K. Ecotourism in Bhutan: Extending its benefits to rural communities. Annals of Tourism Research, 2008, vol. 35, nº 2, p. 489-508.

HARAWAY, D. When species meet. Minneapolis: University of Minnesota Press, 2008.

HEIDEGGER, M. Basic writings: from Being and Time (1927) to The task of thinking (1964). London: Routledge \& Kegan Paul, 1978.

HEIDEGGER, M. Being and Time (trad. Stambaugh, J. y Schmidt, D.J.). New York: State University of New York Press, 1996.

HJORTH, L. Still Mobile: a case study on mobility, home and being away in Shanghai. In WILKEN, R. y GOGGIN, G. Mobile Technology and Place. New York: Routledge, 2012, p. 40-56.

IHDE, D. Bodies in technology. Minneapolis: University of Minnesota Press, 2001.

INGOLD, T.The Perception of the Environment: essays on livelihood, dwelling \& skill. New York: Routledge, 2000.

KÜPERS, W. 'Inter Place' -Phenomenology of Embodied Space and Place as Basis for a Relational Understanding of Leader- and Followship in Organisations.Environment, Space, Place, 2010, vol. 2, nº 1, p. 81-121.

KÜPERS, W. Dancing on the Limen - Embodied and Creative Inter-place as Thresholds of $\mathrm{Be}(\mathrm{com})$ ing: Phenomenological Perspectives on Liminality and Transitional Spaces in Organisations. Tamara, Journal for Critical Organization Inquiry, 2011, vol. 9 (3-4), 45-59.

KÜPERS, W. 2012.Integral Response-abilities for organising and managing Sustainability. In EWEJE, G. y PERRY, M. Business and Sustainability: Concepts, Strategies and Changes, Critical Studies on Corporate Responsibility, Governance and Sustainability. London: Emerald, 2012, p. 25-58. 
LEVIN, D.M. The body's recollection of being: Phenomenological psychology and the deconstruction of nihilism. London: Routledge, 1985.

MACCANNELL, D. The Ethics of Sightseeing. Berkeley: University of California Press, 2011.

MACKAY, K. \& VOGT, C. Information technology in everyday and vacation contexts. Annals of Tourism Research, 2012, vol. 39, n 3, p. 1380-1401.

MALPAS, J. Place and Experience: a philosophical topography. Cambridge, UK.: Cambridge University Press, 1999.

MALPAS, J. Heidegger's Topology: being, place, world. Cambridge, Mass.: MIT Press, 2006.

MALPAS, J. 2012a.Heidegger and the thinking of place: explorations in the topology of being. Cambridge, Mass.: MIT Press, 2012.

MALPAS, J. 2012b. Putting space in place: philosophical topography and relational geography. Environment and Planning D: Society and Space, vol. 30, n 2, p. 226-242.

MASSEY, D. For Space. London: Sage, 2005.

MASSUMI, B. A Shock to Thought: expressions after Deleuze and Guattari. New York: Routledge, 2002.

MCLUHAN, M. Understanding Media: the extensions of man. New York: Routledge, 2008.

MERLEAU-PONTY, M. Phenomenology of Perception. London: Routledge \& Paul, 1962.

MORIN, E. Homeland Earth: A Manifesto for the New Millennium (trad. Anne Brigitte Kern). Cresskill, N.J.: Hampton Press.

MOSCARDO, G. Mindful visitors: Heritage and tourism. Annals of Tourism Research, 1996, vol. 23, $\mathrm{n}^{\circ}$ 2, p. 376-397.

MYDANS, S. Tourism Saves a Laotian City but Saps Its Buddhist Spirit. Annals of Tourism Research, 2008, vol. 33, no 1, p. 144-161.

NASH, D. Anthropology of Tourism. Oxford: Pergamon, 1996.

NEPAL, S.K. Tourism in protected areas: The Nepalese Himalaya. Annals of Tourism Research, 27 (3), p. 661-681.

NIGHTINGALE, A.W. Spectacles of Truth in Classical Greek Philosophy: Theoria in its Cultural Context. Cambridge: Cambridge University Press, 2004. 
ORTNER, S.B. Life and Death on Mt. Everest: Sherpas and Himalayan Mountaineering. Princeton, N.J.: Princeton University Press, 2001.

PERKINS, H. \& BROWN, P. Environmental values and the so-called "True Ecotourist". Journal of Travel Research, 2012, n 51, p. 793-803.

PITMAN, T. \& BROOMHALL, S. Teaching ethics beyond the Academy: Educational tourism, lifelong learning and phronesis. Studies in the Education of Adults, 2011, vol. $43, n^{\circ} 1$, p. 4-17.

PLESSNER, H. Die Stufen des Organischen und der Mensch.Einleitung in die philosophische Anthropologie [The Stages of the Organic and Man: Introduction to Philosophical Anthropology] vol. IV. Frankfurt; Suhrkamp; New York: Gruyter, 1975 [1928].

ROBERSON, S. Defining Travel: Diverse Visions. Oxford, Mississippi: University of Mississippi Press, 2001.

ROJEK, C. The Labour of Leisure: the culture of free time. Los Angeles: Sage Publications, 2010.

SAID, E. Orientalism. New York: Pantheon Books, 1978.

SEAMON, D. A Geography of the Lifeworld: movement, rest, and encounter. London: Groom Helm, 1979.

SENNETT, R. The Culture of the New Capitalism. New Haven, Conn.; London: Yale University Press, 2006.

SHACKLEY, M. The land of Lo, Nepal/Tibet: The first eight months of tourism. Tourism Management, 1994, vol. 15, nº 1, p. 17-26.

SHACKLEY, M. Lo revisited: the next 18 months. Tourism Management, 1995, vol. $16, \mathrm{n}^{\circ} 2$, p. $150-151$.

SHELlER, M. \& URRY, J. Tourism Mobilities: Places to Play, Places in Play. New York: Routledge, 2004.

SIMMEL, G. The Adventure. In FRISBY, D. y FEATHERSTONE, M. Simmel on Culture: selected writings. Thousand Oaks, Calif.: Sage Publications, 1997, p. 221232.

SLOTERDIJK, P. Mobilization of the planet in the spirit of self-intensification. The Drama Review, 2006, vol. 50, n 4, p. 36-43.

SZERSZYNSKI, B. \& URRY, J. 2006. Visuality, mobility and the cosmopolitan: Inhabiting the world from afar. British Journal of Sociology, 2006, n⿳0 57, p. 113-132. 
TERZIDOU, M. \& STYLIDIS, D. Residents' Perceptions of Religious Tourism and its Socio-Economic Impacts on the Island of Tinos.Tourism \& Hospitality: Planning \& Development, 2008, vol. 5, $\mathrm{n}^{\mathrm{o}}$ 2, p. 113-29.

TUCKER, H. Tourists and troglodytes: Negotiating for sustainability.Annals of Tourism Research, 2001, vol. 28, nº 4, p. 868-891.

TURNER, V. Blazing the trail: way marks in the exploration of symbols. Tucson, AR: University of Arizona Press, 1992.

URRY, J. Mobilities. Cambridge, UK: Polity Press, 2007.

URRY, J.The Tourist Gaze 3.0. London: Sage Publications, 2011.

VIRILIO, P. The Information Bomb. London: Verso, 2005.

WILLIAMS, R. Television: technology and cultural form. New York: Schocken Books, 1975.

(C) Copyright Christopher A. Howard y WendelinKüpers, 2015.

C) Copyright Scripta Nova, 2015.

Ficha bibliográfica:

HOWARD, Christopher A. y KÜPERS, Wendelin. En algún lugar entre todas partes y ninguna parte: el viaje en la era de la Gestell o encuadre digital.Scripta Nova. Revista Electrónica de Geografía y Ciencias Sociales. [En línea]. Barcelona: Universidad de Barcelona, 30 de Mayo de 2015, vol. XIX, no 510-2. <http:/www.ub.es/geocrit/sn/sn510-2.pdf>. [ISSN: 1138-9788]. 